\title{
Long-term effects of thoracic sympathectomy on microcirculation in the hands of patients with primary Raynaud disease
}

\author{
Paweł Maga, MD, PhD, ${ }^{\text {a }}$ Jarosław Kużdżał, MD, PhD, ${ }^{\mathrm{b}}$ Rafał Niżankowski, MD, PhD, ${ }^{a}$ Andrzej Szczeklik, MD, PhD,
} and Krzysztof Sładek, MD, PhD

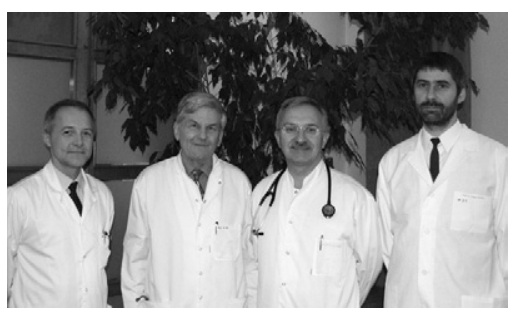

Objective: Videothoracoscopic sympathecomy is a widely used treatment modality in patients with severe Raynaud disease, but the reported late results are less than favorable. There have been no direct studies of the long-term effect of sympathectomy on microcirculation in the hands of these patients.

Methods: In 25 patients with Raynaud disease treated with videothoracoscopic Th2-Th4 sympathectomy, we performed basal laser-Doppler flowmetry and measured the maximal refilling time after 1-minute occlusion measurements preoperatively and at 1 week, 6 months, and 1,2,3, and 5 years after the sympathectomy. The results were compared with the same measurements obtained in the group of 50 healthy individuals.

Results: The patients' symptom severity was assessed by using the visual analogue scale. The basal capillary flow and the maximal refilling time improved after the sympathectomy to a level not different from that seen in the healthy population, and the effect was maintained during the 5-year follow-up period. The patients' symptom severity scores diminished to zero in the early postoperative period and increased to $28 \%$ of their initial value 5 years after the operation.

Conclusions: The videothoracoscopic Th2-Th4 sympathectomy produces excellent and long-lasting improvement of microcirculation function in patients with Raynaud disease. The mild return of symptoms might be due to factors other than the capillary blood flow alterations.

From the Department of Medicine, ${ }^{\text {a }}$ Jagiellonian University, Kraków, Poland, and the Department of Thoracic Surgery, ${ }^{\mathrm{b}}$ Sokołowski Hospital, Zakopane, Poland.

Received for publication Oct 3, 2006; revisions received Dec 4, 2006; accepted for publication Dec 12, 2006.

Address for reprints: Paweł Maga, MD, PhD, Department of Medicine, Jagiellonian University, Kraków, Poland (E-mail: p.maga@ chello.pl).

J Thorac Cardiovasc Surg 2007;133:1428-33 $0022-5223 / \$ 32.00$

Copyright $\odot 2007$ by The American Association for Thoracic Surgery

doi:10.1016/j.jtcvs.2006.12.055
V ideothoracoscopic sympathecomy is a widely used treatment modality in patients with palmar hyperhidrosis and severe Raynaud disease (RD). There is a large body of evidence regarding the safety and effectiveness of this method, but the results in patients with RD are uniformly worse than results in patients with hyperhidrosis. In most studies published to date, however, the results were assessed by using nonobjective tools, such as visual analogue scales (VASs) and different symptom scores. ${ }^{1-8}$ These tools, although having the advantage of giving a general view on patients' self-assessment, might not be accurate in determining the changes in microcirculation itself because of the cumulative influence of many other factors on patients' symptoms. Moreover, data regarding the long-term effect of thoracic sympathectomy on the microcirculation in the hands of patients with RD are lacking. To clarify the long-term effect of thoracic sympathectomy on the microcirculation in the hands of patients with primary RD, we have performed a prospective study using laser-Doppler measurements with a 5-year follow-up period. 


\section{Abbreviations and Acronyms \\ CI = confidence interval \\ $\mathrm{PU}=$ Periflux unit \\ $\mathrm{RD}=$ Raynaud disease \\ VAS $=$ visual analog scale}

\section{Materials and Methods \\ Subjects}

The study protocol was accepted by the institutional review board. All the patients received detailed information regarding diagnostic and therapeutic modalities, and the potential risks and benefits were discussed. Informed consent was obtained from all patients.

The control group consisted of 50 healthy volunteers (25 men and 25 women) with a mean age of 23.4 years (range, 19-27 years).

The RD group consisted of 25 patients with refractory RD referred to our department in the period from 1997 through 2000. There were 7 men and 18 women with a mean age of 27 years (range, 17-49 years). Diagnosis of RD was made based on the medical history of typical symptoms. In all the patients, the primary RD was confirmed by excluding thyroid gland disorders and rheumatoid and autoimmune disease. The diagnostic work-up included physical examination, testing for antinuclear antibodies and rheumatoid factor, and assessment of thyroid hormones levels. Only the patients who did not respond to the medical treatment (bencyclane, Ca-channel blockers, pentoxyphilline, buflomedil, and topical nitroglycerin) were included in the study. Palmar hyperhidrosis was present in all of them. The assessment of microcirculation in the hands consisted of basal capillary flow and the maximal refilling time after 1-minute occlusion measurements.

\section{Technique of Laser-Doppler Examination}

We used the Perimed Master 4001 laser-Doppler flowmeter (Perimed) combined with the Capy Flow software package designed for data acquisition and analysis. The flowmeter was equipped with a standard 633-nm transducer, which was fixed on the level of a nail wall. The test was performed in a soundproof room (temperature, $21^{\circ} \mathrm{C}-23^{\circ} \mathrm{C}$ ) after 15 minutes' rest in a comfortable sitting position. The basal capillary flow was recorded for 5 minutes, and then the test for hyperemia was performed. The pressure cuff was placed on the level of the proximal phalanx and inflated to a pressure of $200 \mathrm{~mm} \mathrm{Hg}$. The 1-minute occlusion was applied at the moment of complete cessation of blood flow. The cuff was deflated in 1 second, and the maximal refilling time was measured (Figure 1). The unit of measurement used for reporting of the blood flow was the Periflux unit (PU). Capillaroscopy was routinely performed. The baseline severity of patients' symptoms, both of RD and those of excessive sweating, was assessed by using the VAS (minimal severity, 0; maximal severity, 10).

\section{Operative Technique}

In the preoperative period, chest radiography, spirometry, and standard blood and urine tests were performed. Videothoracoscopic sympathectomy was performed by the same team of surgeons using the following uniform technique. General anesthesia was induced, and the patient was intubated with a double-lumen
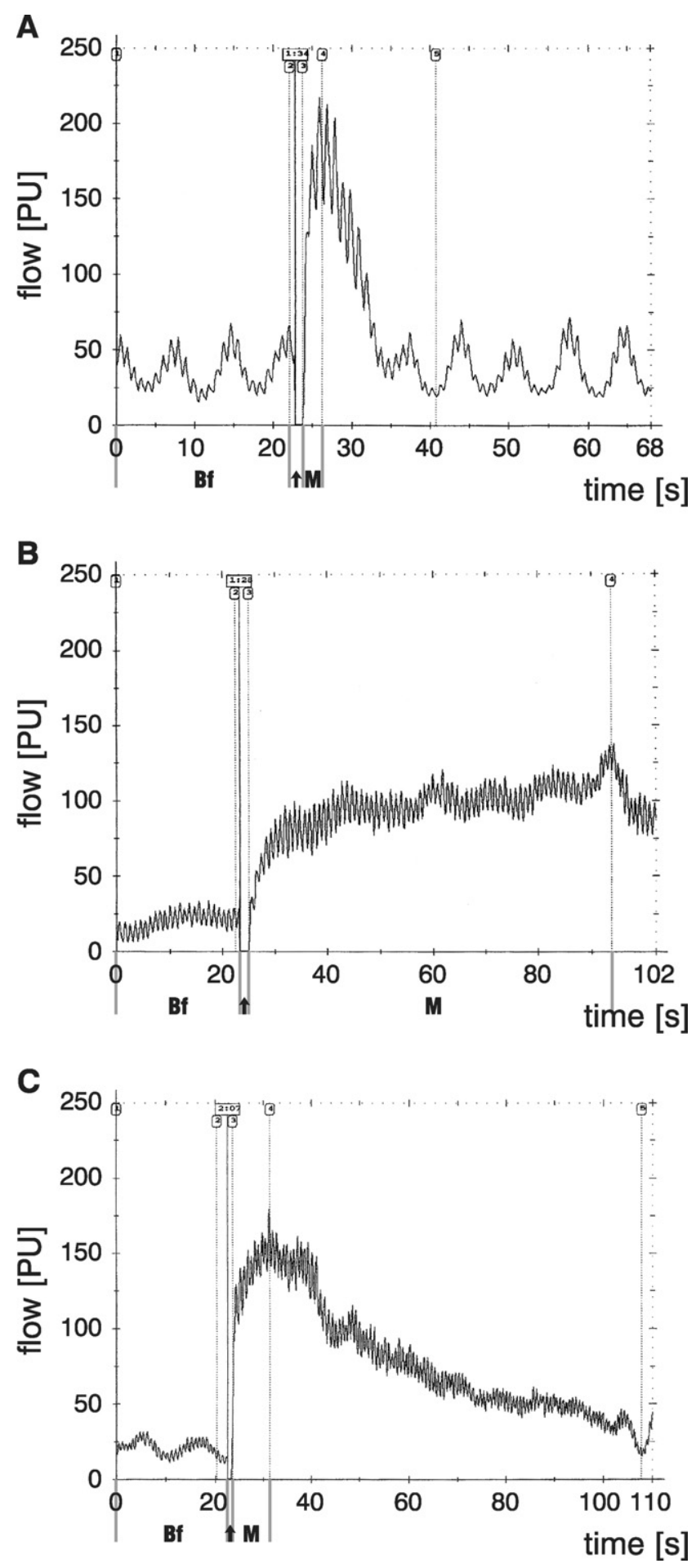

Figure 1. The basal blood flow and the postocclusive hyperemia test. A, Typical curve in a healthy individual. Note the short maximal refilling time after the 1-minute occlusion. $B$, Characteristic curve in a patient with Raynaud disease (RD). The maximal refilling time after the 1-minute occlusion is relatively long. C, A patient with RD 5 years after sympathectomy. The maximal refilling time after the 1-minute occlusion is maintained at the normal level. $P U$, Periflux unit; $B f$, basal flow; $\uparrow$, occlusion; $M$, maximal refilling time. 
TABLE 1. Basal capillary flow and the maximal refilling time after the 1-minute occlusion in the Raynaud disease group: preoperative values compared with measurements 7 days, 6 months, and 1, 2, 3, and 5 years after sympathectomy

\begin{tabular}{lccccccc}
\hline Time period & Preoperative & $\mathbf{7 ~ d}$ & $\mathbf{6 ~ m o}$ & $\mathbf{1 ~ y}$ & $\mathbf{2 ~ y}$ & $\mathbf{3 ~ y}$ & $\mathbf{5} \mathbf{~}$ \\
\hline $\begin{array}{l}\text { Basal capillary } \\
\text { flow* (PU) }\end{array}$ & $12.1(10.6-13.7)$ & $33.2(28.5-38.1)$ & $30.8(25.2-36.5)$ & $28.6(26.3-30.9)$ & $27.6(24.3-30.8)$ & $26.1(22.6-29.5)$ & $23.1(20.7-25.5)$ \\
$\begin{array}{c}\text { Maximal refilling } \\
\text { time* (s) }\end{array}$ & $23.7(18.1-29.3)$ & $6.1(5.3-6.9)$ & $5.4(3.8-6.9)$ & $6.0(4.4-7.6)$ & $6.6(4.5-8.6)$ & $7.0(4.8-9.3)$ & $8.0(5.3-10.8)$ \\
\hline
\end{tabular}

$P U$, Periflux unit. *Mean value (95\% confidence interval).

endotracheal tube and positioned in the standard lateral decubitus position with a roll under the flank. We used the 2-trocar approach: one for the rigid $30^{\circ}$ telescope placed in the midaxillary line in the sixth intercostal space and the second for the coagulating hook placed in the midaxillary line in the fourth intercostal space. After achieving the spontaneous collapse of the lung, the sympathetic trunk was identified. The sympathetic thoracic ganglia (second, third, and fourth) were dissected and coagulated with a cautery. The tissues along the second rib were coagulated with a cautery at the distance of $2.5 \mathrm{~cm}$ to divide the nerve of Kuntz. Bilateral sympathectomy was performed during the same procedure. The $28 \mathrm{~F}$ chest tube was routinely used to allow lung reexpansion. All patients were extubated in the operating theater. The postoperative analgesia regimen included subcutaneous administration of $10 \mathrm{mg}$ of morphine on the first postoperative day. The chest tube was removed on the first day after the operation after radiologic confirmation of full lung re-expansion.

\section{Follow-up}

The follow-up assessments were performed 1 week, 6 months, and 1, 2,3 , and 5 years after the procedure. The basal capillary flow and the maximal refilling time after 1-minute occlusion were measured by using the laser-Doppler technique. Capillaroscopy was performed, and the patients' symptoms were recorded with a VAS.

The results of laser-Doppler measurements were compared with the data obtained in the group of 50 healthy individuals.

\section{Statistical Analysis}

Statistical analysis was performed with the STATISTICA 7.1 software package. For all the variables analyzed, descriptive statistics were calculated: mean value, standard deviation, and $95 \%$ confidence interval (CI). Analysis of variance with repeated measures (multivariate tests) was used for analysis of changes in time. If the effects were significant, the post-hoc test (HSD Tukey test) was used. For comparison with the control group, univariate analysis of variance was used. If the effects were significant, the Dunnett test and the HSD Tukey test were used for detailed hypothesis verification. The level of significance was set at .05.

\section{Results}

In the control group the basal capillary flow was 25.1 PU (95\% CI, 23.1-27.1), and the maximal refilling time after 1-minute occlusion was 4.8 seconds (95\% CI, 4.5-5.2).

In the RD group the preoperative basal capillary flow was 12.1 PU (95\% CI, 10.6-13.7), and the maximal refilling time after 1-minute occlusion was 23.7 seconds $(95 \%$
CI, 18.1-29.3). The preoperative VAS score for excessive sweating, as well as for symptoms of Raynaud phenomenon, was 10 in all patients.

All patients were available for the 5-year follow-up. The basal capillary flow at 7 days, 6 months, and 1, 2, 3, and 5 years after sympathectomy was, respectively, $33.2 \mathrm{PU}(95 \%$ CI, 28.5-38.1), 30.8 PU (95\% CI, 25.2-36.5), 28.6 PU (95\% CI, 26.3-30.9), 27.6 PU (95\% CI, 24.3-30.8), 26.1 PU (95\% CI, 22.6-29.5), and 23.1 PU (95\% CI, 20.7-25.5; Table 1 and Figure 2,A). The Tukey test has shown a significant difference for each follow-up measurement compared with the preoperative values $(P=.000026)$ and no significant difference between any pair of postoperative measurements $(P \leq .00001)$. Compared with the control group, the basal capillary flow in the RD group was significantly greater 1 week and 6 months after sympathectomy $(P=.000019$ and .00072 , respectively) and not significantly different during the rest of the follow-up $(P=$ $.46-.99)$.

The maximal refilling time at 7 days, 6 months, and 1, 2, 3 , and 5 years after sympathectomy was, respectively, 6.1 seconds (95\% CI, 5.3-6.9), 5.4 seconds (95\% CI, 3.8-6.9), 6.0 seconds (95\% CI, 4.4-7.6), 6.6 seconds (95\% CI, 4.58.6), 7.0 seconds (95\% CI, 4.8-9.3), and 8.0 seconds $(95 \%$ CI, 5.3-10.8; Table 1 and Figure 2, B). The Tukey test has shown a significant difference for each follow-up measurement compared with the preoperative values $(P<.000026)$ and no significant difference between any pair of postoperative measurements $(P=.61-1.0)$. There was no difference in the maximal refilling time between any of the postoperative measurements in the RD group and those in the healthy control group $(P=.058-.99)$.

The results of patients' symptom severity with the VAS for Raynaud phenomenon and for hyperhidrosis are presented in the Figure 3. The difference between the preoperative values and any of the postoperative measurements was significant $(P<.05)$.

Compensatory hyperhidrosis was noted in 7 (28\%) of 25 patients after sympathectomy and was mild in all of them.

\section{Discussion}

Several authors assessed the microcirculation using different indirect techniques, including evaporation and skin con- 

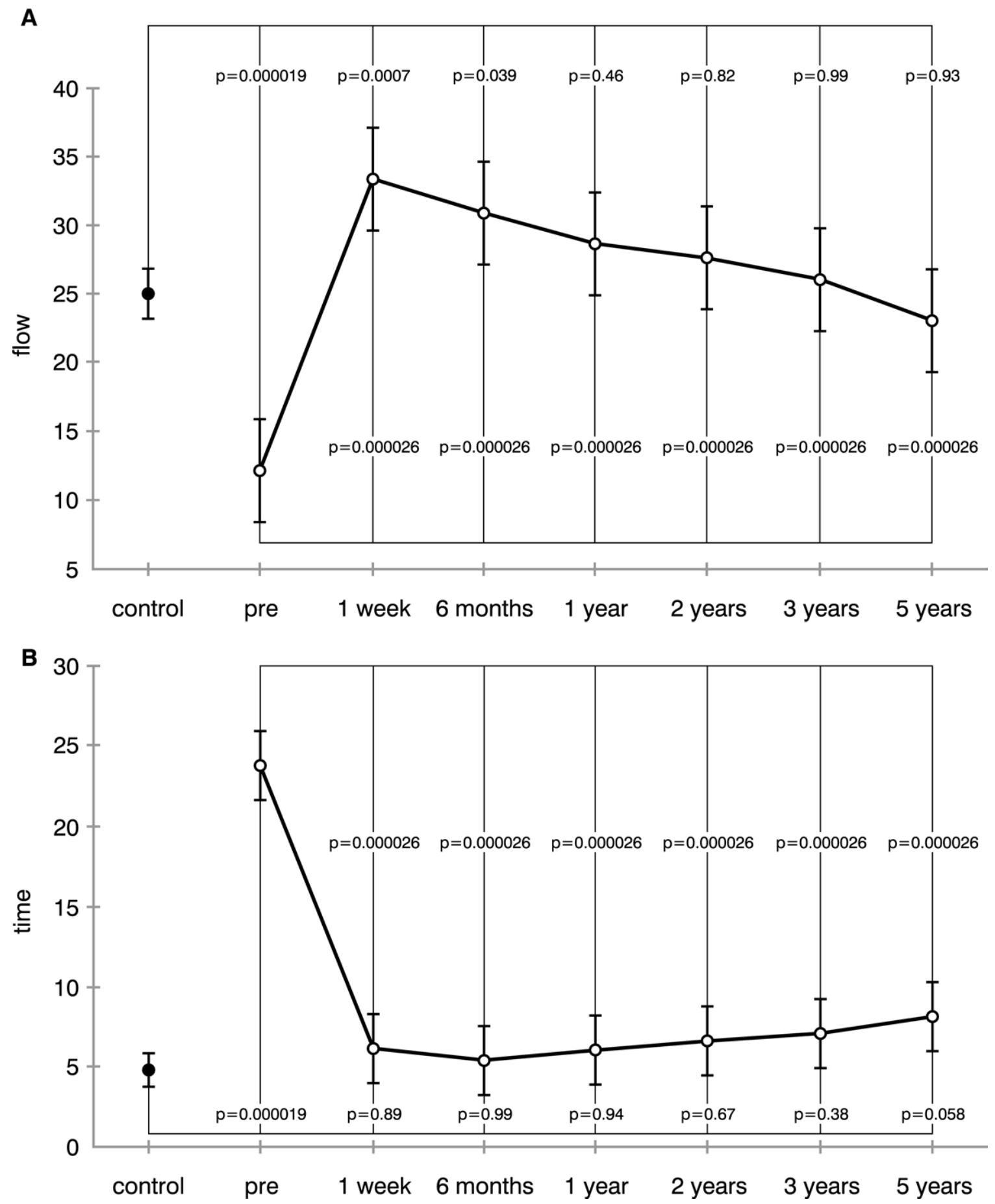

Figure 2. A, Basal capillary flow in 25 patients with Raynaud disease (RD). The follow-up values are significantly higher than the preoperative values and are higher or not significantly different than those in the healthy control group. B, The maximal refilling time after 1-minute occlusion in 25 patients with RD. The follow-up values are significantly lower than the preoperative values and not significantly different than those in the healthy control group. 


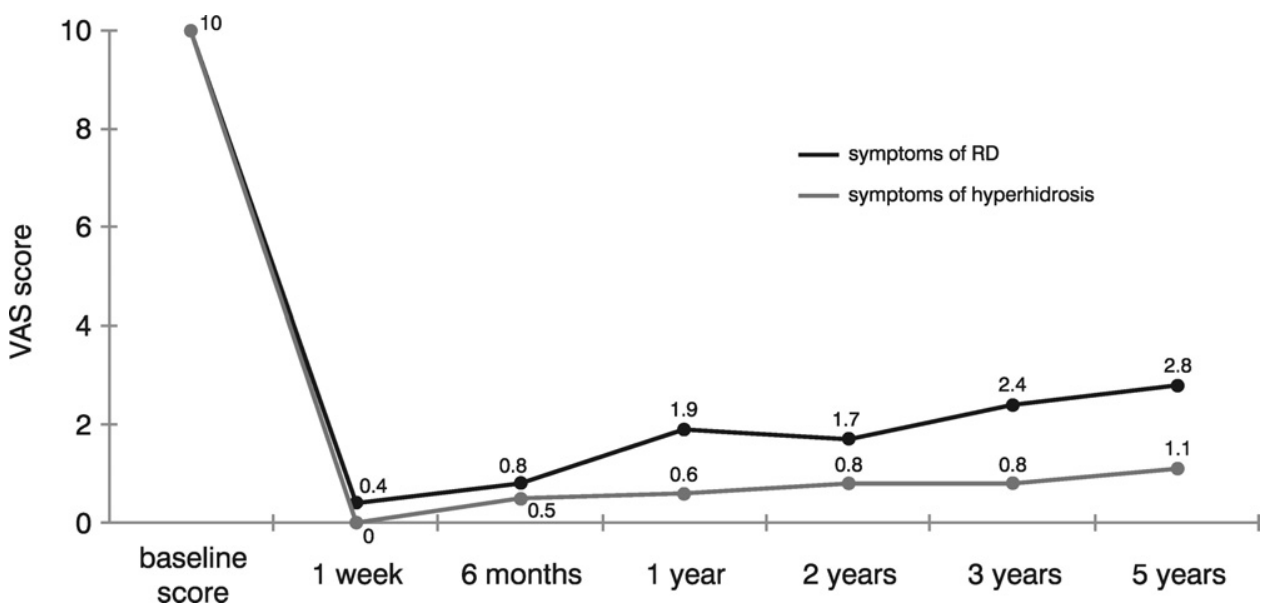

Figure 3. The visual analog scale (VAS) score of Raynaud disease (RD) symptoms and symptoms of hyperhidrosis. The RD symptoms, being almost totally abolished directly after the sympathectomy, increase slightly over time, reaching $28 \%$ of their initial severity after $\mathbf{5}$ years of follow-up. The increase of hyperhidrosis symptoms is less noticeable.

ductance, ${ }^{9}$ pulse oximetry, ${ }^{10}$ skin temperature, ${ }^{11-18}$ infrared termography, ${ }^{19,20}$ and the sympathetic skin response. ${ }^{21-23}$ The only technique of direct measurement of capillary blood flow is laser-Doppler flowmetry, ${ }^{12,24-27}$ the likely standard modality in studies of microcirculation.

In studies assessing the usefulness of laser-Doppler flowmetry in the diagnosis of RD, blood flow alterations have been shown in both primary and secondary RD. ${ }^{28,29}$ The diagnostic value of this technique was confirmed in other studies. $^{24,30,31}$ This is consistent with our results, showing a significant difference in the basal capillary flow and the maximal refilling time after 1-minute occlusion between patients with RD and healthy control subjects. In one study the difference between the maximal refilling time in patients with primary RD and healthy control subjects did not reach the level of significance; this could have been due to the small number of patients $(n=13) .^{32}$

Data regarding the late results of thoracic sympathectomy in patients with RD based on studies with subjective assessment modalities are generally discouraging. The longterm recurrence rate in patients with RD, assessed by using self-assessment questionnaires, ranged from $55 \%{ }^{33}$ to $82.1 \% .^{34}$ In other series persistent or recurrent symptoms were present after 6 months to 1 year in all patients treated with sympathectomy. ${ }^{35-37}$ This has led Coffman ${ }^{38}$ to the conclusion that "surgical sympathectomy in RD has not been beneficial." The reasons for this very high recurrence rate are unknown. However, in a study assessing resympathectomy for recurrent palmar hyperhidrosis, Shim and colleagues $^{39}$ found that in $86.1 \%$ of patients, surgical errors were made during the primary operation (intact sympathetic chain in $11.1 \%$, incomplete sympathectomy in $16.7 \%$, partial reattachment of the chain in $16.7 \%$, improper ganglion location in $11.1 \%$, and surgical clip slipping out in $30.5 \%){ }^{39}$ This emphasizes the importance of a meticulous surgical technique for avoiding symptom recurrence.

Contrary to the opinions mentioned above, our results have shown significant and long-lasting improvement in the basal capillary blood flow and the maximal refilling time after 1-minute occlusion. The postoperative values were not significantly different from those in the healthy control group, and this effect was maintained during the entire 5-year follow-up period.

The analysis of the VAS scores shows that symptoms of hyperhidrosis were almost permanently abolished (only $11 \%$ of their initial severity after 5 years of follow-up), whereas symptoms of RD reappeared with time but with mild intensity, reaching $28 \%$ of their initial severity after 5 years of follow-up. The discrepancy between patients' symptoms and the objectively measured capillary blood flow might be due to the cumulative effect of different factors, including psychogenic factors, on the symptoms. Although the capillary blood flow is the most important parameter, other factors might contribute to the mild worsening in the patients' self-assessment. The lack of correlation between symptoms and objectively measured variables regarding $\mathrm{RD}$ and palmar hyperhidrosis was also reported by other authors. ${ }^{21,40}$

\section{Conclusions}

1. Thoracic Th2-Th4 sympathectomy in patients with RD results in significant improvement of capillary blood flow, reaching a level that does not differ from that seen in healthy subjects.

2. This effect remains at a level not different than that seen in the healthy population over a 5-year follow-up period. 
3. The symptoms of RD, as self-assessed by the patients, reoccur to a moderate degree with time after the sympathectomy.

\section{References}

1. Schmidt J, Bechara FG, Altmeyer P, et al. Endoscopic thoracic sympathectomy for severe hyperhidrosis: impact of restrictive denervation on compensatory sweating. Ann Thorac Surg. 2006;81:1048-55.

2. Kumagai K, Kawase H, Kawanishi M. Health-related quality of life after thoracoscopic sympathectomy for palmar hyperhidrosis. Ann Thorac Surg. 2005;80:461-6.

3. Chang DB, Yang PC, Yu CJ, et al. Ultrasonography and ultrasonographically guided fine-needle aspiration biopsy of impalpable cervical lymph nodes in patients with non-small cell lung cancer. Cancer. 1992;70:1111-4.

4. Dumont P, Denoyer A, Robin P. Long-term results of thoracoscopic sympathectomy for hyperhidrosis. Ann Thorac Surg. 2004;78:1801-7.

5. Young O, Neary P, Keaveny TV, et al. Evaluation of the impact of transthoracic endoscopic sympathectomy on patients with palmar hyperhidrosis. Eur J Vasc Endovasc Surg. 2003;26:673-6.

6. Leseche G, Castier Y, Thabut G, et al. Endoscopic transthoracic sympathectomy for upper limb hyperhidrosis: limited sympathectomy does not reduce postoperative compensatory sweating. J Vasc Surg. 2003;37:124-8.

7. Gossot D, Toledo L, Fritsch S, et al. Mediastinoscopy vs thoracoscopy for mediastinal biopsy. Results of a prospective nonrandomized study. Chest. 1996;110:1328-31.

8. Rex LO, Drott C, Claes G, et al. The Boras experience of endoscopic thoracic sympathicotomy for palmar, axillary, facial hyperhidrosis and facial blushing. Eur J Surg Suppl. 1998;580:23-6.

9. Krogstad AL, Skymne BS, Goran Pegenius BS, et al. Evaluation of objective methods to diagnose palmar hyperhidrosis and monitor effects of botulinum toxin treatment. Clin Neurophysiol. 2004;115:1909-16.

10. Klodell CT, Lobato EB, Willert JL, et al. Oximetry-derived perfusion index for intraoperative identification of successful thoracic sympathectomy. Ann Thorac Surg. 2005;80:467-70.

11. Eisenach JH, Pike TL, Wick DE, et al. A comparison of peripheral skin blood flow and temperature during endoscopic thoracic sympathotomy. Anesth Analg. 2005;100:269-76.

12. Crandall CG, Meyer DM, Davis SL, et al. Palmar skin blood flow and temperature responses throughout endoscopic sympathectomy. Anesth Analg. 2005;100:277-83.

13. Chuang KS, Liu WC, Liu JC. Alteration in cardiovascular function and body surface temperature during percutaneous stereotactic upper thoracic ganglionectomy and sympathectomy in palmar hyperhidrotic patients. Clin Auton Res. 2004;14:259-63.

14. Saiz-Sapena N, Vanaclocha V, Panta F, et al. Operative monitoring of hand and axillary temperature during endoscopic superior thoracic sympathectomy for the treatment of palmar hyperhidrosis. Eur J Surg. 2000;166:65-9.

15. Lu K, Liang CL, Lee TC, et al. Changes of bilateral palmar skin temperature in transthoracic endoscopic T-2 sympathectomy. $J$ Neurosurg. 2000;92:44-9.

16. Lu K, Liang CL, Cho CL, et al. Patterns of palmar skin temperature alterations during transthoracic endoscopic T2 sympathectomy for palmar hyperhidrosis. Auton Neurosci. 2000;86:99-106.

17. Wong CW. The second thoracic sympathetic ganglion determines palm skin temperature in patients with essential palmar hyperhidrosis. J Auton Nerv Syst. 1997;67:121-4.

18. Linder A, Friedel G, Toomes H. Palmar thermometry for intraoperative success control of thoracic sympathectomy. Thorac Cardiovasc Surg. 1993;41:242-4.

19. Kruger S, Fronek KS, Schmelz M, et al. Differential effects of surgical sympathetic block at the T2 and T4 level on vasoconstrictor function. Clin Auton Res. 2003;13(suppl 1):I79-82.
20. Shiau YC, Hsieh JF, Tsai SC, et al. Technetium-99m methoxy-isobutylisonitrile chest single photon emission computed tomography to detect mediastinal lymph node metastasis in patients with non-small cell lung cancer: comparison with computed tomography. Anticancer Res. 2000;20:3751-4.

21. Lewis DR, Irvine CD, Smith FC, et al. Sympathetic skin response and patient satisfaction on long-term follow-up after thoracoscopic sympathectomy for hyperhidrosis. Eur J Vasc Endovasc Surg. 1998;15: 239-43.

22. Steinert HC, Hauser M, Allemann F, et al. Non-small cell lung cancer: nodal staging with FDG PET versus CT with correlative lymph node mapping and sampling. Radiology. 1997;202:441-6.

23. Lefaucheur JP, Fitoussi M, Becquemin JP. Abolition of sympathetic skin responses following endoscopic thoracic sympathectomy. Muscle Nerve. 1996;19:581-6.

24. Weber WA, Neverve J, Sklarek J, et al. Imaging of lung cancer with fluorine-18 fluorodeoxyglucose: comparison of a dual-head gamma camera in coincidence mode with a full-ring positron emission tomography system. Eur J Nucl Med. 1999;26:388-95.

25. Ng I, Yeo TT. Palmar hyperhidrosis: intraoperative monitoring with laser Doppler blood flow as a guide for success after endoscopic thoracic sympathectomy. Neurosurgery. 2003;52:127-131.

26. Gazelius B, Stange K, Lind G, et al. Endoscopic transthoracic sympathicotomy and peripheral microcirculation: effects of electric sympathetic chain stimulation, thermocoagulation and anaesthetic agents. Acta Neurochir (Wien). 2002;144:589-594.

27. Bornmyr S, Svensson H, Soderstrom T, et al. Finger skin blood flow in response to indirect cooling in normal subjects and in patients before and after sympathectomy. Clin Physiol. 1998;18:103-7.

28. Engelhart M, Kristensen JK. Raynaud's phenomenon: blood supply to fingers during indirect cooling, evaluated by laser Doppler flowmetry. Clin Physiol. 1986;6:481-8.

29. Boignard A, Salvat-Melis M, Carpentier PH, et al. Local hyperemia to heating is impaired in secondary Raynaud's phenomenon. Arthritis Res Ther. 2005;7:R1103-12.

30. Binaghi F, Cannas F, Mathieu A, et al. Correlations among capillaroscopic abnormalities, digital flow and immunologic findings in patients with isolated Raynaud's phenomenon. Can laser Doppler flowmetry help identify a secondary Raynaud phenomenon? Int Angiol. 1992;11:186-94.

31. Wollersheim H, Reyenga J, Thien T. Postocclusive reactive hyperemia of fingertips, monitored by laser Doppler velocimetry in the diagnosis of Raynaud's phenomenon. Microvasc Res. 1989;38:286-95.

32. Wigley FM, Wise RA, Mikdashi J, et al. The post-occlusive hyperemic response in patients with systemic sclerosis. Arthritis Rheum. 1990; 33:1620-1625.

33. Sayers RD, Jenner RE, Barrie WW. Transthoracic endoscopic sympathectomy for hyperhidrosis and Raynaud's phenomenon. Eur J Vasc Surg. 1994;8:627-31.

34. Matsumoto Y, Ueyama T, Endo M, et al. Endoscopic thoracic sympathicotomy for Raynaud's phenomenon. J Vasc Surg. 2002;36:57-61.

35. Lowell RC, Gloviczki P, Cherry KJ Jr, et al. Cervicothoracic sympathectomy for Raynaud's syndrome. Int Angiol. 1993;12:168-72.

36. Claes G, Drott C, Gothberg G. Thoracoscopic sympathicotomy for arterial insufficiency. Eur J Surg Suppl. 1994;572:63-4.

37. Claes G. Indications for endoscopic thoracic sympathectomy. Clin Auton Res. 2003;13(suppl 1):I16-9.

38. Coffman JD. Raynaud's phenomenon. An update. Hypertension. 1991; 17:593-602.

39. Shim SS, Lee KS, Kim BT, et al. Non-small cell lung cancer: prospective comparison of integrated FDG PET/CT and CT alone for preoperative staging. Radiology. 2005;236:1011-9.

40. Leesmans E, Bartelink ML, Wollersheim H, et al. The relationship between subjective vasospastic complaints and finger blood flow measurements in Raynaud's phenomenon. Neth J Med. 1993;43:13-7. 